OPEN ACCESS

Edited by: Andrew Zloza,

Rush University Medical Center,

United States

Reviewed by:

Hussein Al-Akhrass,

University of Turku, Finland

Spyridon Kampantais,

Aristotle University of Thessaloniki,

Greece

*Correspondence:

Kai Gan

18795882599@163.com

Bin Xu

njxbseu@seu.edu.cn

Weijun Qin

qinwj@fmmu.edu.cn

Specialty section:

This article was submitted to Cancer Molecular Targets

and Therapeutics,

a section of the journa

Frontiers in Oncology

Received: 14 January 2021

Accepted: 12 August 2021

Published: 01 September 2021

Citation:

Gan K, Gao Y, Liu K, Xu B and Qin W (2021) The Clinical Significance and

Prognostic Value of HER2 Expression in Bladder Cancer: A Meta-Analysis and a Bioinformatic Analysis.

Front. Oncol. 11:653491.

doi: 10.3389/fonc.2021.653491

\section{The Clinical Significance and Prognostic Value of HER2 Expression in Bladder Cancer: A Meta-Analysis and a Bioinformatic Analysis}

\author{
Kai Gan ${ }^{1 *}$, Yue Gao ${ }^{2}$, Kuangzheng $\mathrm{Liu}^{2}$, Bin $\mathrm{Xu}^{2^{*}}$ and Weijun $\mathrm{Qin}^{1 *}$ \\ ${ }^{1}$ Department of Urology, Xijing Hospital, Fourth Military Medical University, Xi'an, China, ${ }^{2}$ Surgical Research Center, Institute of \\ Urology, Medical School of Southeast University, Nanjing, China
}

Objective: Human Epidermal Growth Factor Receptor 2 (HER2) is highly expressed in multiple malignancies and associated with patients' prognosis, but its role in bladder cancer $(\mathrm{BCa})$ remains elusive. We conducted this meta-analysis to explore the clinical significance and prognostic value of HER2 in $\mathrm{BCa}$.

Methods: PubMed was searched for studies published between January 1, 2000 and January 1, 2020. The odds ratios (ORs) and hazard ratios (HRs) with 95\% confidence intervals $(95 \% \mathrm{Cls})$ were used to investigate the relationship between HER2 and BCa pathological features. TCGA was mined for the information regarding as well.

Results: Our study included 14 articles enrolling 1398 people. Expression of HER2 is higher in bladder cancer than in normal tissues. HER2 over-expression is associated with CIS, multifocal tumor, large tumor size, high tumor stage and grade, lymph node metastasis, progression, recurrence and papillary tumor. We could not find a significant association between HER2 expression and survival time in BCa patients.

Conclusions: Our meta and bioinformatic analysis indicated that HER2 expression was related to pathological malignancy and poor prognosis in BCa.

Keywords: bladder cancer, HER2, clinical significance, prognostic value, meta-analysis

\section{INTRODUCTION}

Bladder cancer is the ninth most common malignancy worldwide (1), accounting for $4 \%$ of all cancer deaths among the male population in the United States in 2019 (2). According to the latest statistics published recently, 83,730 estimated new cases and 17,200 related deaths were expected in the United States in 2021 (3).

\footnotetext{
Abbreviations: BCa, bladder cancer; HER2, Human Epidermal Growth Factor Receptor 2; OR, odds ratio; HR: hazard ratio; CI: confidence interval; TCGA, The cancer genome atlas; RFS, recurrence-free survival; NMIBC, non-muscle invasive bladder cancer; MIBC, muscle invasive bladder cancer; PRISMA: Preferred Reporting Items for Systematic Reviews and Meta-Analysis; PICO: population, intervention, comparison, results; IHC, immunohistochemistry; ASCO, American Society of Clinical Oncology; CAP, American College of Pathology; NOS, Newcastle - Ottawa Quality Assessment Scale; CIS, Carcinoma in situ; $\mathrm{AR}$, androgen receptor; EGFR, epidermal growth factor receptor; TKI, tyrosine kinase inhibitors; DDX6, DEAD/H-box RNA helicase 6; FISH, fluorescence in situ hybridization; FISH, fluorescence in situ hybridization.
} 
Currently, the treatment outcomes associated with bladder cancer are not satisfactory. Even after complete transurethral resection of bladder tumors or even secondary surgery, 33\% of these patients will develop muscle-invasive bladder cancer (MIBC) (4). In previous studies, some urinary bladder cancer biomarkers, such as NUMA1 and CFHR1, have been proposed. The study of molecular markers in bladder cancer is gradually becoming hot (5). However, specific pathological markers clearly associated with bladder cancer are still lacking. We need better relevant markers to assess the risk of bladder cancer and predict cancer development.

The human epidermal growth factor receptor-2 (HER2) is known to contribute to cell growth, survival, and migration as a member of the transmembrane receptors (6). In addition, HER2 has been extensively studied as a tumor therapeutic target and is considered to act as a very important prognostic and therapeutic marker for breast cancer. The expression of HER2 molecules in breast cancer can already be precisely detected $(7,8)$. Overexpression of the HER2 gene is highly correlated with malignancy and poor prognosis of breast cancer. HER2 can be involved in the signaling pathway of breast cancer cells, increasing their proliferative capacity (7). HER2 has also been studied in esophageal and gastric cancers. In metastatic esophagogastric cancer with HER2 protein overexpression, pabolizumab can be efficiently combined with trastuzumab as well as chemotherapy. This combination therapy can benefit patients more than previous monotherapies $(9,10)$. Referring to the results of the relevant discussions on pathology at the 2nd International Consultation of Bladder Cancer, HER2 overexpression was associated with highgrade uroepithelial carcinoma and muscle invasion (11). A number of other similar studies have been conducted in the past and reached similar conclusions.

A previous study has reported that HER2 expression was associated with poor prognosis in $\mathrm{BCa}$ (12). In another study, the authors claimed that HER2 could be used as a diagnostic marker in bladder cancer especially NMIBC (13). Thus, HER2 could be considered as a useful biomarker for clinical prediction in $\mathrm{BCa}$. However, the specific role of HER2 in bladder cancer needs to be demonstrated by strong evidence-based medical studies. In recent years, studies on HER2 in bladder cancer have continued to emerge in numerous journals. Thus, we performed a meta-analysis and bioinformatic analysis to assess the prognostic value of HER2 gene and protein expression in BCa patients.

\section{MATERIALS AND METHODS}

\section{Search Strategy}

This meta-analysis was performed following the convention of PRISMA (Preferred Reporting Items for Systematic Reviews and Meta-Analysis) guidelines. An electronic search of databases from PubMed from January 2000 to January 2020 was conducted. According to the PICO framework (population, intervention, comparison, results), we used specific terms including "HER2", "bladder cancer", "prognosis", "clinical significance" to search target literature. The search was restricted to English-language articles only. Two authors independently screened the title and abstract of each article and reviewed the full text. The eligibility of each article was evaluated. If there was a disagreement, the third author would join the discussion and decide whether we should include that literature.

\section{Inclusion Criteria}

Full texts of these studies were read carefully to determine whether the articles met the following inclusion criteria: (1) The study must focus on patients diagnosed with bladder cancer; (2) HER2 protein expression was detected by immunohistochemistry (IHC). The expression level of HER2 must be clear. Referring to the "ASCO/ CAP Guidelines Consensus on Breast Cancer HER2 Detection” which was jointly issued by the American Society of Clinical Oncology (ASCO) and the American College of Pathology (CAP) on December 11, 2006, if more than $10 \%$ of tumor cells show membrane staining, we call it "positive". Otherwise, we call it "negative". (3) Containing patient information, tumor classification, staging, and prognosis-related conditions.

\section{Exclusion Criteria}

The exclusion criteria were set as follows: (1) The study was a review article, case report, letter, comment or conference abstract. (2) Patients were included in another study.

\section{Data Extraction}

The extracted data for each study included the first author's name, publication year, the proportion of cells with stained cell membrane after IHC, number of including cases, the median or mean age of patients, the percent of male patients, the median or mean follow-up, type of bladder cancer, outcome (Table $\mathbf{1}$ ).

\section{Study Quality Assessment}

In the quality evaluation, we used the Newcastle - Ottawa Quality Assessment Scale (NOS) to evaluate the quality of the included literature. The NOS scale covers three key areas, including selection, comparability, and exposure/results. Studies with a score of seven or above are considered to be high quality on this rating scale. The results indicated that the quality of literatures we selected was not low (Table 2).

\section{Usage of TCGA Database}

TCGA database, a publicly available platform, was applied to investigate HER2 gene expression levels in BCa. We used $\mathrm{R}$ (version 3.6.3) software to Processing these data. Wilcoxon rank sum test was used to compare the expression differences of HER2 in various cases of classification. Log-rank test was used to analyze the survival database. $\mathrm{P}<0.05$ was regarded as statistically significant.

\section{Statistical Analysis}

We used the Stata 15.0 software for data analysis. For dichotomous variables including gender and percentage of carcinoma in situ (CIS), multifocal tumors, tumor size, stage, grade, lymph node metastases, and lymph vascular invasion, the odds ratio (OR) and 95\% confidence interval (CI) were adopted. For comparison of time-related prognostic information which 


\begin{tabular}{|c|c|c|c|c|c|c|c|}
\hline Reference & Method & Number & Age & Male\% & $\begin{array}{l}\text { Follow-up } \\
\text { (months) }\end{array}$ & Tumor type & Outcomes \\
\hline Ding et al. (14) & $\| \mathrm{HC}>10 \%$ & 238 & 68 (Median) & 81.9 & 47 (median) & non-muscle-invasive bladder cancer (NMIBC) & Tumor size; recurrence; progression; grade \\
\hline Kolla et al. (15) & $\| H C>10 \%$ & 90 & 58 (mean) & 95.6 & 46 (median) & muscle invasive urinary bladder cancer & grade; Iymph node metastasis \\
\hline Krüger et al. (16) & $\mathbb{H C}>10 \%$ & 138 & 64 (Median) & 80.4 & 53 (mean) & muscle-invasive bladder carcinoma & grade; lymph node metastasis \\
\hline Lim et al. (17) & $\| H C \geq 50 \%$ & 141 & 68.9 (mean) & 86.5 & 73.3 (mean) & non-muscle-invasive bladder cancer & progression; recurrence; tumor size; grade \\
\hline Hegazy et al. (18) & $\mid H C>20 \%$ & 88 & not specific & not specific & 36 (median) & non-muscle invasive (NMI) bladder cancer & tumor recurrence and progression; grade \\
\hline Paul et al. (19) & $\mid \mathrm{HC}>30 \%$ & 178 & 71 (mean) & not specific & 82 (mean) & non-muscle-invasive bladder cancer & Recurrence; progression \\
\hline El et al. (20) & $\| \mathrm{HC}>30 \%$ & 103 & 63 (Median) & 93.2 & not specific & non-muscle-invasive and muscle-invasive bladder cancer & Tumor size; Tumor grade \\
\hline Inoue et al. (21) & $\mid H C>10 \%$ & 95 & not specific & 72.6 & 36 (median) & muscle-invasive bladder carcinoma & recurrence condition \\
\hline Behnsawy et al. (22) & $\| H C>10 \%$ & 161 & not specific & 85.1 & not specific & non-muscle-invasive bladder cancer & recurrence condition \\
\hline Olsson et al. (23) & $\| \mathrm{HC}>30 \%$ & 201 & 73 (Median) & 83 & 58 (median) & non-muscle-invasive bladder cancer & $\begin{array}{l}\text { tumor size, multiplicity, possible presence of histologically } \\
\text { proven recurrence and progression; grade }\end{array}$ \\
\hline Moustakas et al. (24) & $\| H C>10 \%$ & 48 & 68 (mean) & 97.3 & not specific & non-muscle-invasive urothelial cell carcinoma of the bladder & Grade at diagnosis; recurrence-free survival (RFS) \\
\hline Soria et al. (25) & $\| \mathrm{HC}>30 \%$ & 354 & $\begin{array}{l}66.3 \\
\text { (Median) }\end{array}$ & 81 & 123 (mean) & $\begin{array}{l}\text { muscle invasive and very high-risk non-muscle invasive } \\
\text { bladder cancer }\end{array}$ & oncological outcomes; grade \\
\hline Bolenz et al. (26) & $\| \mathrm{HC}>10 \%$ & 198 & $\begin{array}{l}66.7 \\
\text { (Median) }\end{array}$ & 78.8 & 48.7 (mean) & non-muscle-invasive and muscle-invasive bladder cancer & recurrence; lymph node metastasis; grade \\
\hline Abdelrahman et al. (27) & $\| \mathrm{HC}>30 \%$ & 60 & 52 (Median) & 71.70 & 44(mean) & Non-muscle-invasive bladder cancer (NMIBC) & $\begin{array}{l}\text { tumor recurrence, progression, recurrence-free survival (RFS) } \\
\text { and progression-free survival (PFS); grade }\end{array}$ \\
\hline
\end{tabular}

IHC, immunohistochemistry.

TABLE 2 | Newcastle - Ottawa Quality Assessment Scale of the included literature.

\begin{tabular}{|c|c|c|c|c|c|c|c|c|c|}
\hline & $\begin{array}{l}\text { Representativeness } \\
\text { of the exposed } \\
\text { cohort }\end{array}$ & $\begin{array}{c}\text { Selection of } \\
\text { the non- } \\
\text { exposed } \\
\text { cohort }\end{array}$ & $\begin{array}{l}\text { Ascertainment } \\
\text { of exposure }\end{array}$ & $\begin{array}{c}\text { Demonstration that outcome } \\
\text { of interest was not present at } \\
\text { start of study }\end{array}$ & $\begin{array}{l}\text { Comparability of cohorts on the basis } \\
\text { of the design or analysis (study } \\
\text { adjusts for age } e^{*}, \text { sex }^{*} \text { ) }\end{array}$ & $\begin{array}{l}\text { Assessment } \\
\text { of outcome }\end{array}$ & $\begin{array}{l}\text { Was follow-up long } \\
\text { enough for out- } \\
\text { comes to occur }\end{array}$ & $\begin{array}{l}\text { Adequacy of } \\
\text { follow up of } \\
\text { cohorts }\end{array}$ & Total \\
\hline $\begin{array}{l}\text { Abdelrahman } \\
\text { et al. (27) }\end{array}$ & * & * & * & * & ** & * & * & - & 8 \\
\hline $\begin{array}{l}\text { Bolenz et al. } \\
\text { (26) }\end{array}$ & * & * & * & * & ** & * & * & - & 8 \\
\hline $\begin{array}{l}\text { Soria et al. } \\
\text { (25) }\end{array}$ & * & * & * & * & ** & * & * & * & 9 \\
\hline $\begin{array}{l}\text { Moustakas } \\
\text { et al. (24) }\end{array}$ & - & * & * & * & ** & * & - & * & 7 \\
\hline $\begin{array}{l}\text { Olsson et al. } \\
\text { (23) }\end{array}$ & * & * & * & * & ** & * & * & - & 8 \\
\hline $\begin{array}{l}\text { Behnsawy } \\
\text { et al. (22) }\end{array}$ & * & * & * & * & ** & * & - & * & 8 \\
\hline $\begin{array}{l}\text { Inoue et al. } \\
(21)\end{array}$ & - & * & * & * & ** & * & * & * & 8 \\
\hline El et al. (20) & * & * & * & * & ** & * & * & * & 9 \\
\hline $\begin{array}{l}\text { Paul et al. } \\
\text { (19) }\end{array}$ & * & * & * & * & ** & * & * & * & 9 \\
\hline
\end{tabular}




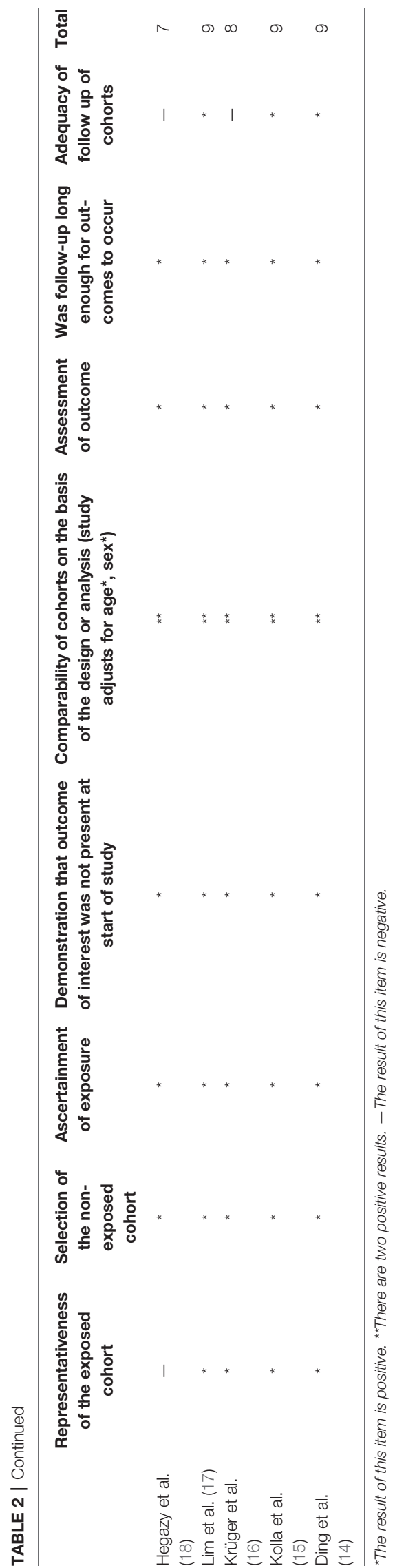

contained recurrence, progression, and recurrence-free survival (RFS), hazard ratio (HR) and 95\% CI were applied (28). All statistical tests were two-sided, and a $P$ value $<0.05$ was considered statistical significance. Forest plots showed the results of research analysis and publication bias was visually evaluated using funnel plot. The heterogeneity was assessed by $\mathrm{I}^{2}$ statistics, and funnel plots were used to test publication bias. As noted by the Cochrane Handbook (29), when heterogeneity was less than $40 \%$, a fixed effect model was recommended for Metaanalysis. Otherwise, a random effect model should be used.

\section{RESULTS}

\section{Search Results}

The search strategy retrieved 80 unique citations, of which 58 were excluded after the first screening based on abstracts and titles, leaving 22 for full article review. Finally, we included 14 articles, 1398 patients for our study. A study selection flowchart is presented in Figure 1.

\section{Comparison of Gender Differences Among Patients}

There was no association between HER2 protein expression and the gender of the patients ( $\mathrm{OR}=1.04 ; 95 \% \mathrm{CI}: 0.76-1.42 ; \mathrm{p}=0.80)$ (14-16, 20, 21, 25-27) (Figure 2A).

\section{Oncology-Related Features}

We found that HER2 positive rate was high in both carcinoma in situ (CIS) $(\mathrm{OR}=0.62 ; 95 \% \mathrm{CI}: 0.42-0.92 ; \mathrm{p}=0.02)(14,17,18,20$, 21, 26, 27) (Figure 2B) and multifocal tumors (OR=0.45; 95\% CI:0.30-0.68; p<0.01) $(14,17,18,21,27)$ (Figure 2C). HER2 expression was also associated with large tumor size $(>3 \mathrm{~cm})$ $(\mathrm{OR}=0.40 ; 95 \%$ CI:0.26-0.63; p<0.01) $(14,17,20,23,27)$

(Figure 2D). In the HER2 positive tumors, the proportion of Ta stage was significantly lower than that in the negative tumors $(\mathrm{OR}=2.52 ; 95 \% \mathrm{CI}: 1,58-4.01 ; \mathrm{p}<0.01) \quad(14,21,24,25,27)$

(Figure 3A). Furthermore, HER2 expression was linked with high tumor grade $(\mathrm{OR}=0.23$; 95\% CI:0.15-0.35; $\mathrm{p}<0.01)(14-18$, 20, 23-27) (Figure 3B) and lymph node metastasis $(\mathrm{OR}=0.52$; 95\% CI:0.38-0.71; p<0.01) $(15,16,21,25,26)$ (Figure 3C). But the expression level of HER2 protein was not associated with lymph vascular invasion (OR=0.11; 95\% CI:0.00-3.05; $\mathrm{p}=0.19)$ $(17,26)$ (Figure 3D).

\section{Comparison of Prognosis}

Patients with high expression of HER2 protein had a greater risk of tumor recurrence (HR=0.76; 95\% CI:0.63-0.92; $\mathrm{p}<0.01)(14$ $17-19,21-23,26,27)$ (Figure 4A) and progression $(\mathrm{HR}=0.31$ 95\% CI:0.18-0.54;p<0.01) $(14,17-19,21-23,27)$ (Figure 4B) than those with low expression of HER2. HER2 expression was associated with a low 2-year recurrence-free survival (RFS) rate $(\mathrm{HR}=1.31 ; 95 \% \mathrm{CI}: 1.01-1.70 ; \mathrm{p}=0.04) \quad(24-27)$ (Figure 4C). Progression, recurrence and survival conditions have different impact between MIBC and NMIBC cohorts, so we did subgroup 


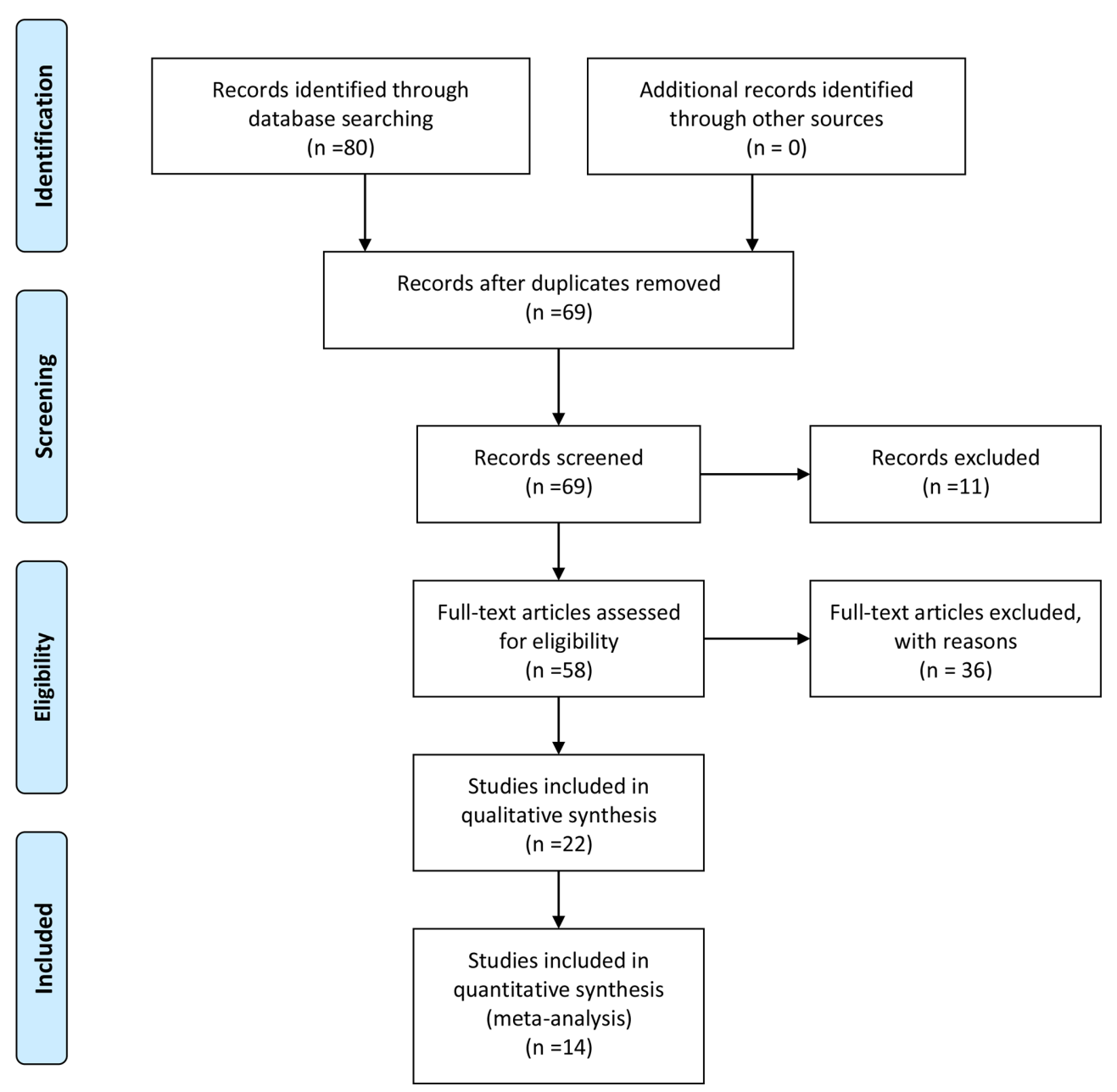

FIGURE 1 | Study selection flowchart.

analysis in NMIBC patients. The results were as follows: recurrence $(\mathrm{HR}=0.77 ; 95 \%$ CI:0.61-0.97; $\mathrm{p}=0.02) \quad(14,17,18$, 21-23, 27) (Figure 4D); 2-year recurrence-free survival (RFS) $(\mathrm{HR}=1.22 ; 95 \% \mathrm{CI}: 0.87-1.71 ; \mathrm{p}=0.25)(24,27)$ (Figure 4E).

\section{TCGA Database Analysis Results}

HER2 gene expression in BCa tissues was significantly higher than that in normal tissues $(\mathrm{P}=0.007)$ (Figure 5A). HER2 expression was significantly elevated in patients with high pathologic stage $(\mathrm{P}=0.002)$ (Figure 5B). HER2 expression in patients with $\mathrm{Bca}$ was independent of gender, which was consistent with our results $(\mathrm{P}=0.081)$ (Figure 5C). Overexpression of HER2 gene also correlated with lymph node metastases, lymph vascular invasion, and tumor subtype $(\mathrm{P}<0.05)$ (Figure 5D-F). There were no significant differences in overall survival, disease-specific survival, and progress-free interval between different levels of HRE2 gene amplification groups $(\mathrm{P}>0.05)$ (Figure 5G-I).

\section{Publication Bias}

Funnel plots were used to detect publication bias, as shown in Figure 6. Evidence showed that funnel plots for each group were symmetrical, with no significant risk of bias. This result suggested that the results of this meta-analysis were reliable.

\section{DISCUSSION}

Our study focused on the relationship of HER2 expression in bladder cancer between oncological characteristics and patient prognosis. We included 14 articles, 1398 patients for our study. We also used the TCGA database for analysis. Combining our meta-analysis and TCGA database exploration, we came to a number of conclusions.

First, based on our findings, we learned that HER2 expression was significantly higher in bladder cancer than in normal tissue at both the transcriptional and translational levels. Many years 


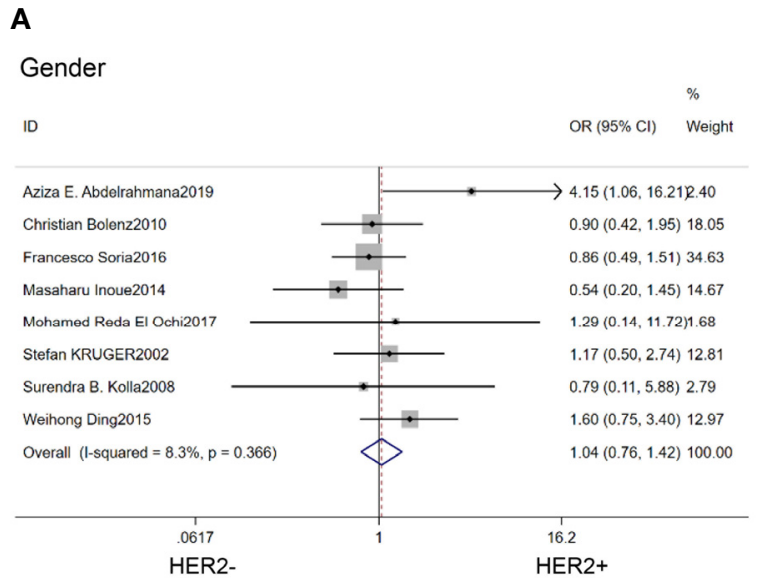

\section{C}

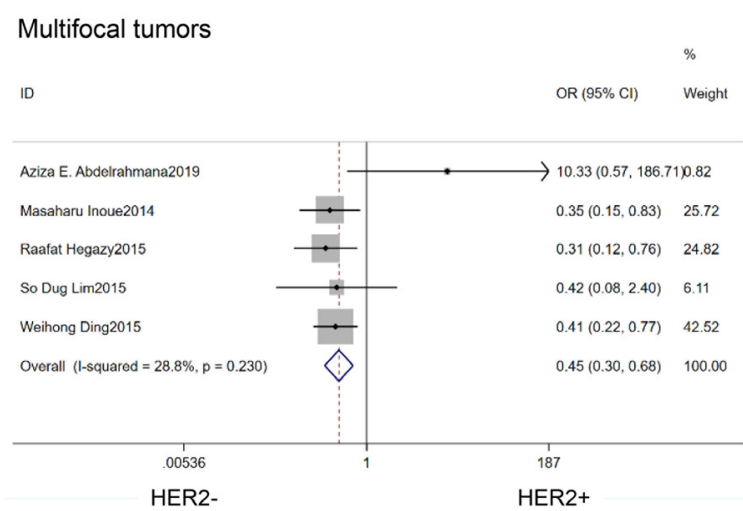

B
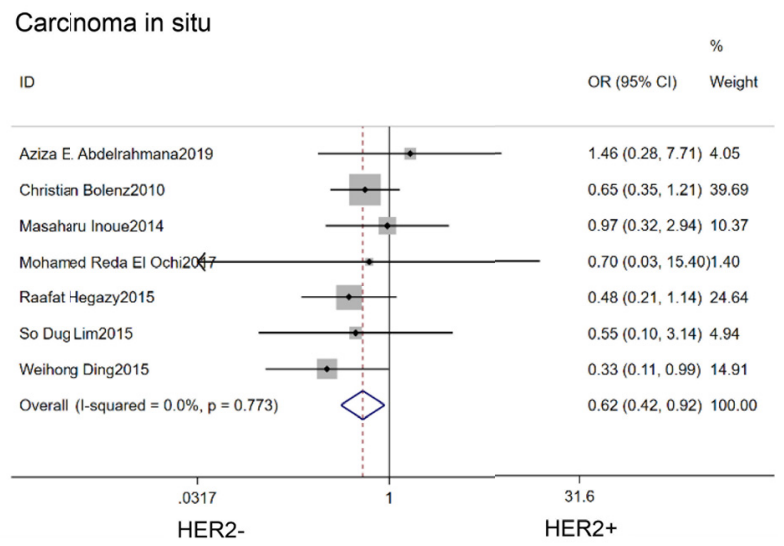

D

Tumor size

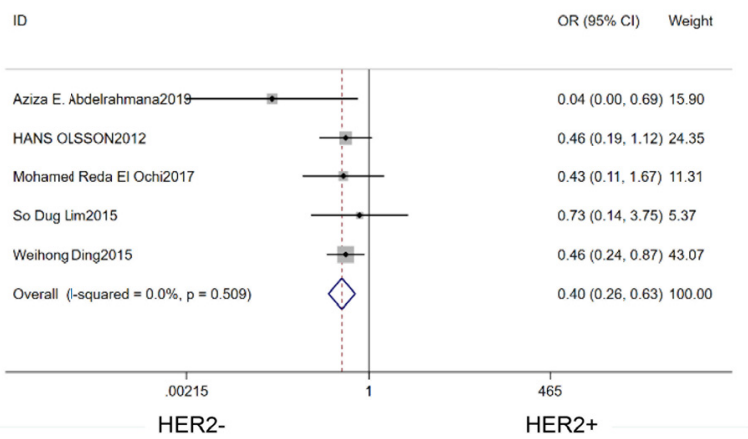

FIGURE 2 | Forest plots describing the correction of HER2 protein expression with gender (A), carcinoma in situ (B), multifocal tumors (C) and large tumor size (D). $\mathrm{OR}$, odds ratio; $\mathrm{Cl}$, confidence interval.

ago, Eissa et al. found significant overexpression of HER2 in the malignant bladder cancer group compared to the benign and normal groups by enzyme immunoassay (13). In 2019, Sanguedolce et al. also declared that HER2 expression was significantly elevated in bladder cancer and this phenomenon was associated with tumor development (30). Thus, it can be seen that HER2 expression is relavent for bladder cancer.

We could not find any relationship between HER2 expression and gender in BCa patients, either by genetic testing or IHC. However, differently, HER2 overexpression was more commonly observed in male gastric cancer patients of Japan (31). Fan et al. came to the same conclusion in a related survey of the Chinese population (32). Thus, the relationship between HER2 in pancancer and gender is unclear and needs to be further validated by large-scale clinical studies.

Our meta-analysis displayed that HER2 protein tended to be highly expressed in CIS and multifocal tumors. Similar conclusions have been drawn from previous studies $(14,26)$. CIS is a flat, noninvasive urothelial carcinoma with a high probability of progression. And CIS is usually multifocal, the incidence of muscle infiltration in CIS tends to be significantly higher than in Ta and T1 stage bladder cancer $(33,34)$. Also, multifocal CIS has proven to be associated with a high risk of recurrence in $\mathrm{BCa}$ (35). We concluded that overexpression of HER2 in BCa often appeared in CIS and multifocal tumors which predicted a high risk of tumor recurrence.

In our meta-analysis study, HER2 protein expression was clearly related to tumor size, grade, and stage of BCa. Also, by analyzing the $\mathrm{BCa}$ data from TCGA, we found that HER2 gene expression was associated with tumor stage. The details of the relevant mechanism need to be confirmed in further study.

We found that high expression of both HER2 gene and protein was related to lymph node metastasis in BCa. A previous study has indicated that the probability of HER2 positivity in lymph node metastases was significantly higher than in the primary site of $\mathrm{BCa}$, too (36). Interestingly, this also seemed to be true for other kinds of tumors. Lu et al. claimed that HER2 may serve as a potential biomarker for lymph node metastasis in colorectal cancer (37). In examining the relationship between HER2 and lymphovascular invasion, we 
A

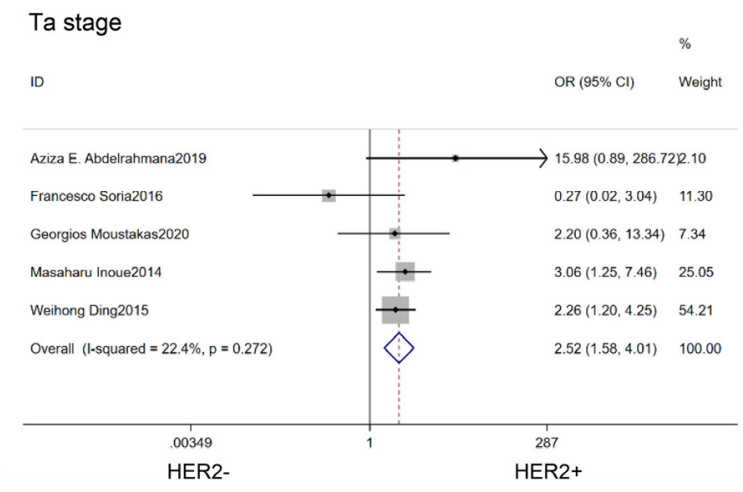

\section{C}

Lymph node metastases

ID

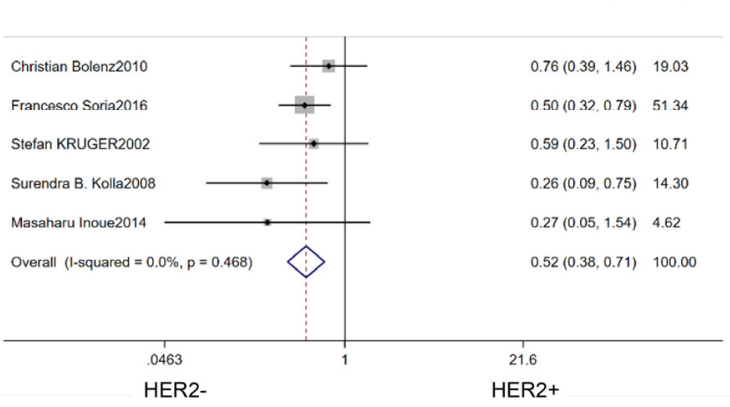

B

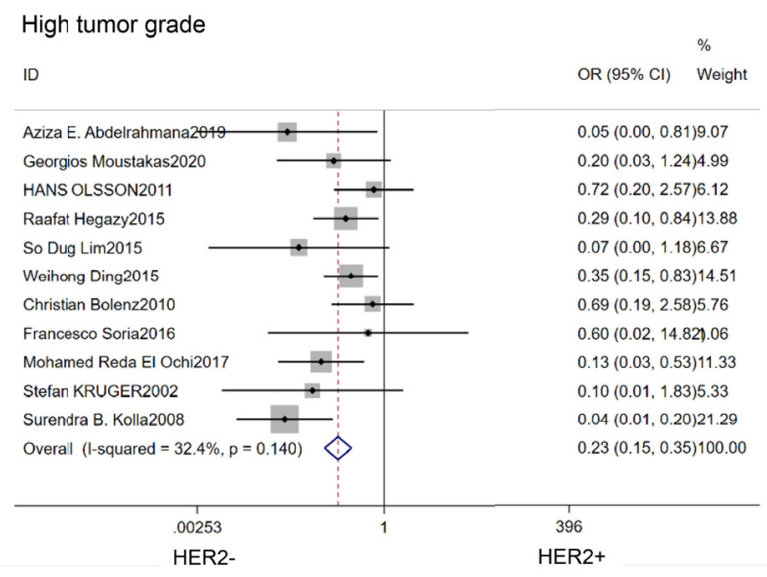

D

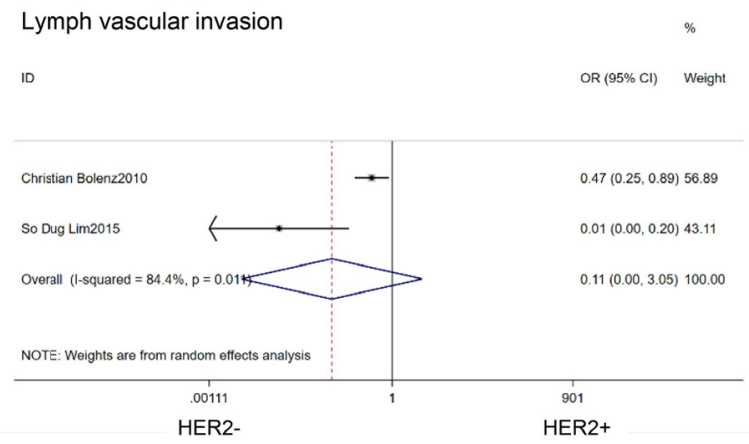

FIGURE 3 | Forest plots describing the correction of HER2 protein expression with stage (A), grade (B), lymph node metastases (C) and lymph vascular invasion (D). OR, odds ratio; $\mathrm{Cl}$, confidence interval.

found inconsistent results between gene amplification and protein levels. The enhancement of HER2 gene expression seemed to be connected with lymphovascular invasion.

We also found that HER2 protein overexpression was highly correlated with tumor recurrence, progression, and RFS in patients with BCa. A recent study has indicated that HER2 expression in bladder cancer cells was associated with tumor recurrence. In this published literature, Kim et al. discussed that there was a correlation between HER2 and immune checkpoint proteins in $\mathrm{BCa}$ (38). Similar findings have also been reported over the last few years. Nedjadi et al. revealed that HER2 expression was associated with disease aggressiveness (39). The results of subgroup analysis were consistent. We found that HER2 expression did not affect RFS in NMIBC. TCGA data analysis indicated that HER2 gene was not connected with overall survival, disease-specific survival and progress-free interval in BCa patients.

Due to the conflicting results, variances in HER2 expression among BCa patients remain unclear. After consulting relevant literatures, we speculated that the differential expression of HER2 among people might be related to a wide variety of molecules such as androgen receptor (AR). The AR signaling pathway has been proven to promote tumor development and progression in $\mathrm{BCa}$ (40). Zheng et al. claimed that AR activation upregulated the expression of HER2 in bladder cancer cells (41). It has been proved that inhibiting AR pathway can successfully control the occurrence and development of bladder cancer, and can be synergistic with the cisplatin chemotherapy regimen (42). There were other molecules that have been shown to be associated with HER2. For example, the research results of Memon et al. suggested that the final outcome of patients with high HER2 gene expression in $\mathrm{BCa}$ depended on the expression of HER3 and HER4 (43).

Although HER2-associated molecular immunotherapy for $\mathrm{BCa}$ has not been put to clinical use, the idea has been proposed for a long time and is still emerging $(16,44)$. Nagasawa et al. found that TAK-165 (a potent inhibitor of HER2) significantly inhibited the growth of bladder cancer cell. It may be a hopeful agent for BCa (45). Tsai et al. constructed a HER2targeted, envelope-modified retroviral vector which carried the 


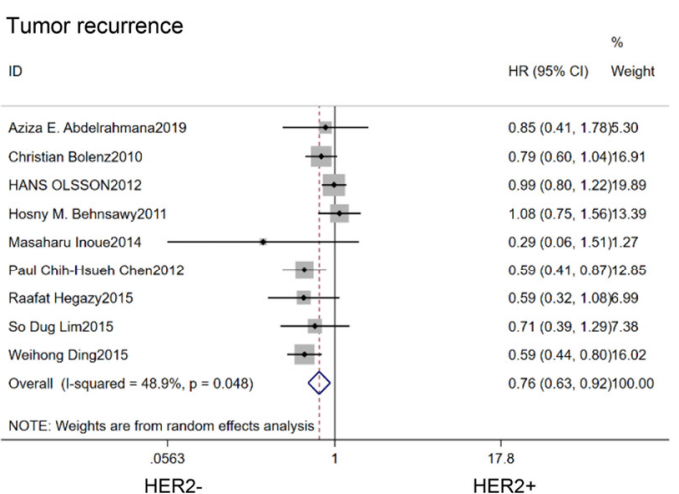

C

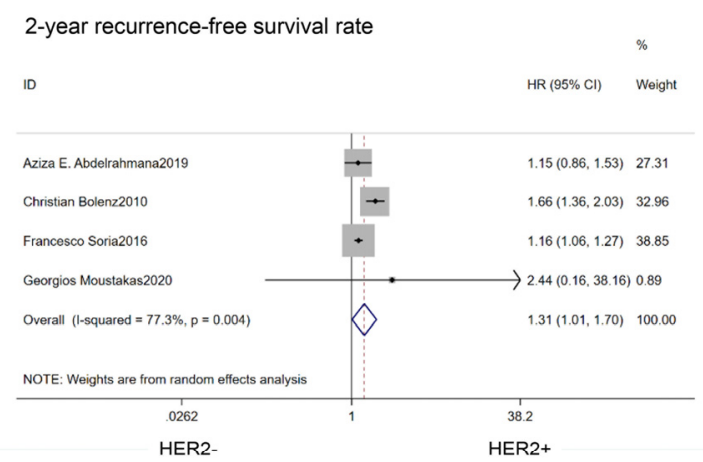

E

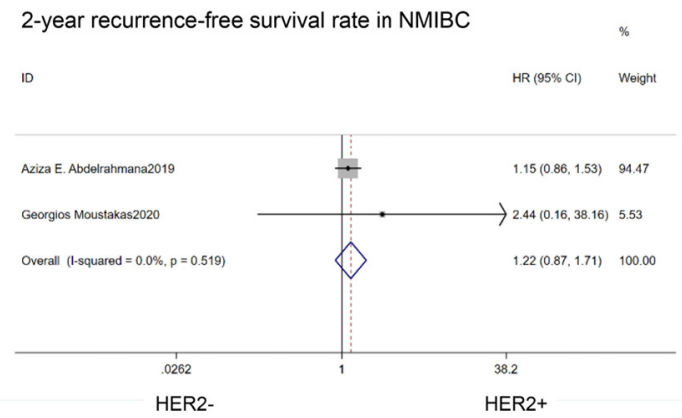

B

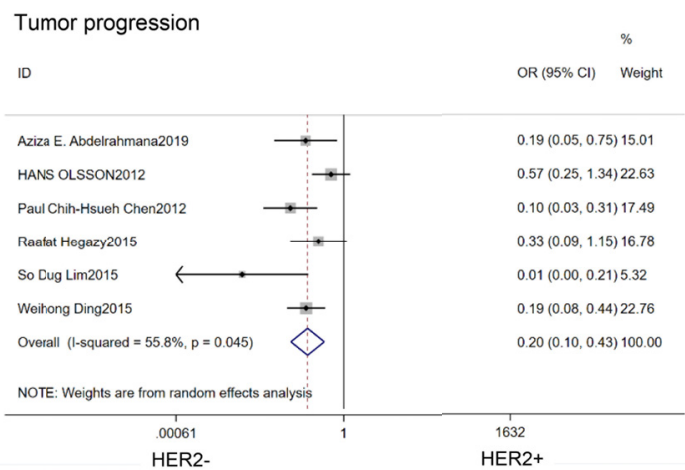

D

Tumor recurrence in NMIBC

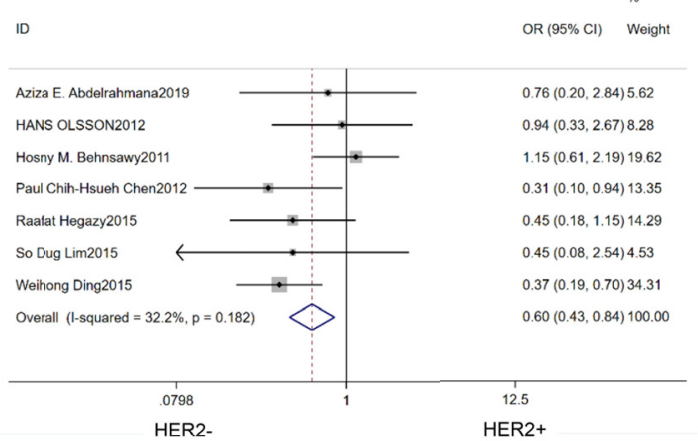

FIGURE 4 | Forest plots describing the correction of HER2 protein expression with recurrence (A), progression (B), 2-year RFS (C), recurrence in NMIBC (D), 2-year RFS in NMIBC (E). RFS, recurrence-free survival; NMIBC, non-muscle invasive bladder cancer. OR, odds ratio; HR, hazard ratio; Cl, confidence interval.

interleukin (IL)-12 gene for the treatment of BCa in mice (46). A prior study demonstrated that epidermal growth factor receptor (EGFR) TKI (tyrosine kinase inhibitors) blocked both radiationactivated EGFR and HER2 signaling and inhibited the growth of BCa cells in vitro (47). T-DM1, a drug consisting of the HER2 antibody trastuzumab in combination with a cytotoxic agent, has been indicated to be superior to trastuzumab alone in breast cancer by Hayashi et al. (48). A recent study pointed out that the conjugates of epidermal growth factor and anthrax toxin could be a new approach against BCa in dogs (49). Indoleamine 2, 3-dioxygenase and programmed death ligand-1 have been proved to be associated with HER2 protein. All of these three molecules can be used as directions for immunotherapy in BCa (38).

There are many other studies focusing on HER2-mediated mechanisms of cancer which open the door to new drug development. Mika et al. found the SORLA-dependent molecular pathway in HER2-driven breast cancer cells (50). Yoshihisa et al. 
A

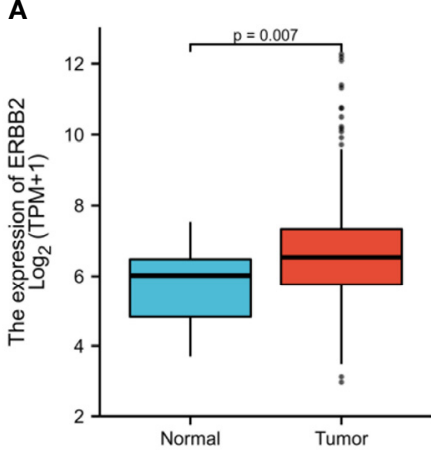

D

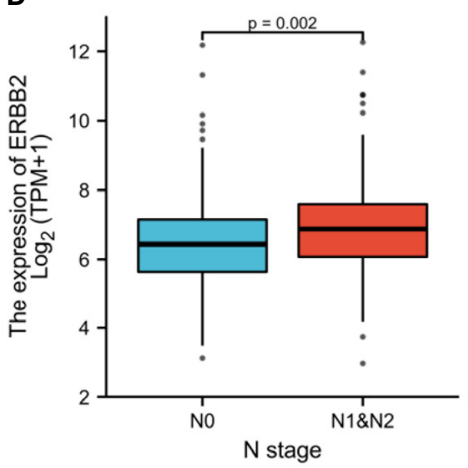

G

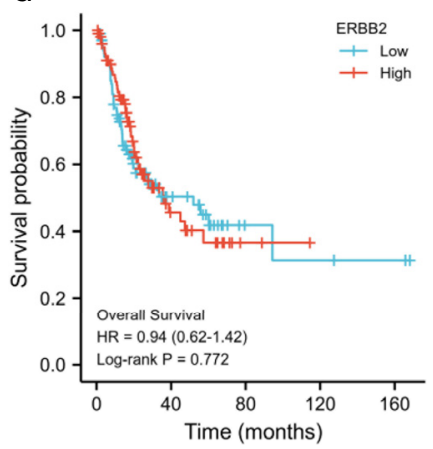

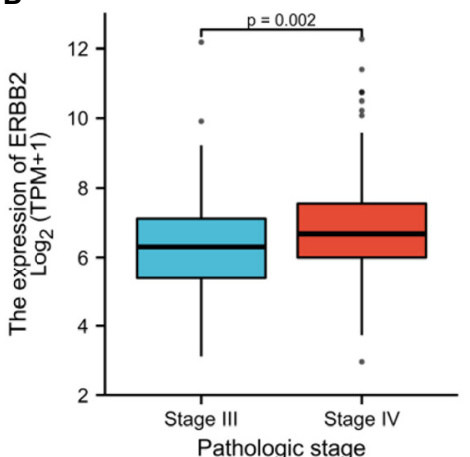

E

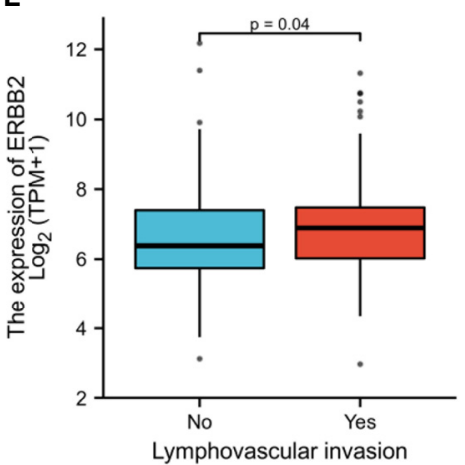

H

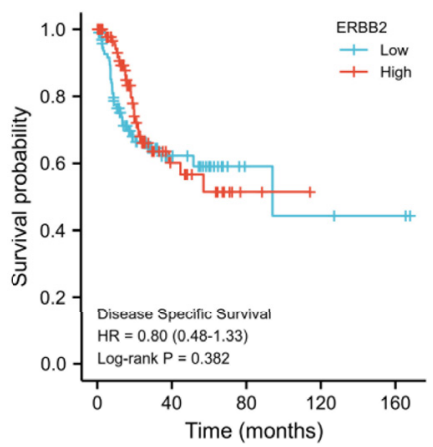

C
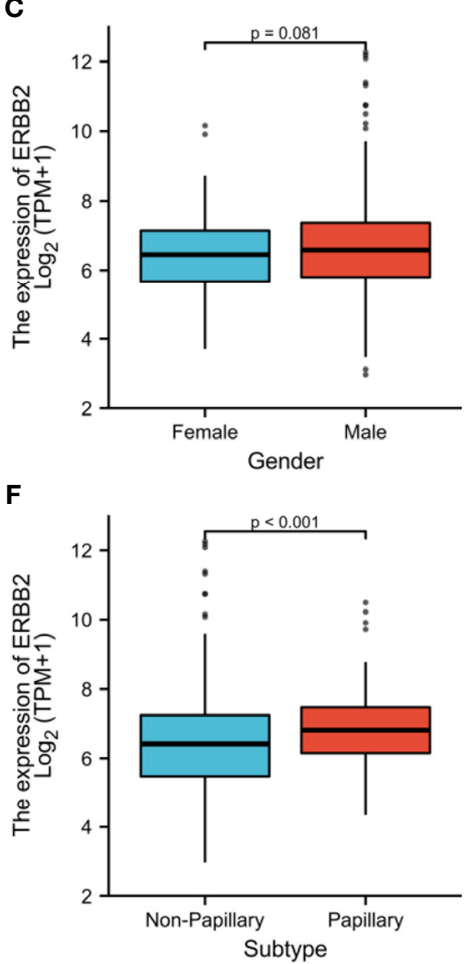

I

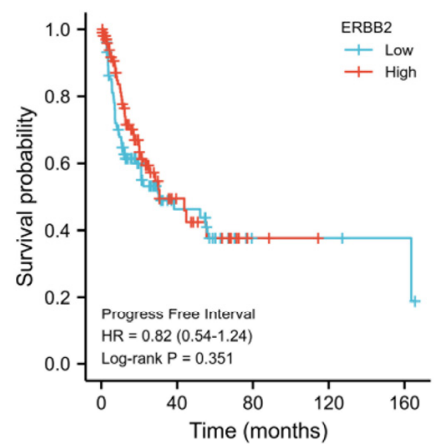

FIGURE 5 | TCGA analysis of differences about HER2 gene expression between cancer and normal tissues (A), stage III and IV (B), male and female (C), NO and N1\&2 tumor (D), LVI and no-LVI (E) and subtypes (F). Survival conditions were also compared: overall survival (G), disease specific survival $(\mathbf{H})$ and progress free interval (I). ERBB2: HER2, Human Epidermal Growth Factor Receptor 2; LVI, lymph vascular invasion; HR, hazard ratio.

suggested that syn-miR-143 down-regulated the expression of HER2 through silencing DEAD/H-box RNA helicase 6 (DDX6) in HER2-positive gastric cancer cells (51). Thus, it seems that HER2-related tumor-targeting research is still very promising. The mechanism of HER2 in bladder cancer still needs to be further explored.

There are several limitations in our study. First, we only searched PubMed database, the number of included literatures is not big enough. Second, the search was restricted to Englishlanguage articles, we may have missed some documents written in other languages. Finally, in the meta-analysis literature we included, HER2 expression was measured by the IHC method only. It has been suggested that the results of IHC and fluorescence in situ hybridization (FISH) were not completely consistent when detecting HER2 expression in bladder cancer $(52,53)$. A combination of FISH assays is needed for further research in the future.

\section{CONCLUSION}

HER2 showed enhanced expression level in bladder cancer in comparison with normal samples and its overexpression was tightly associated with CIS, multifocal tumor, large tumor size, 

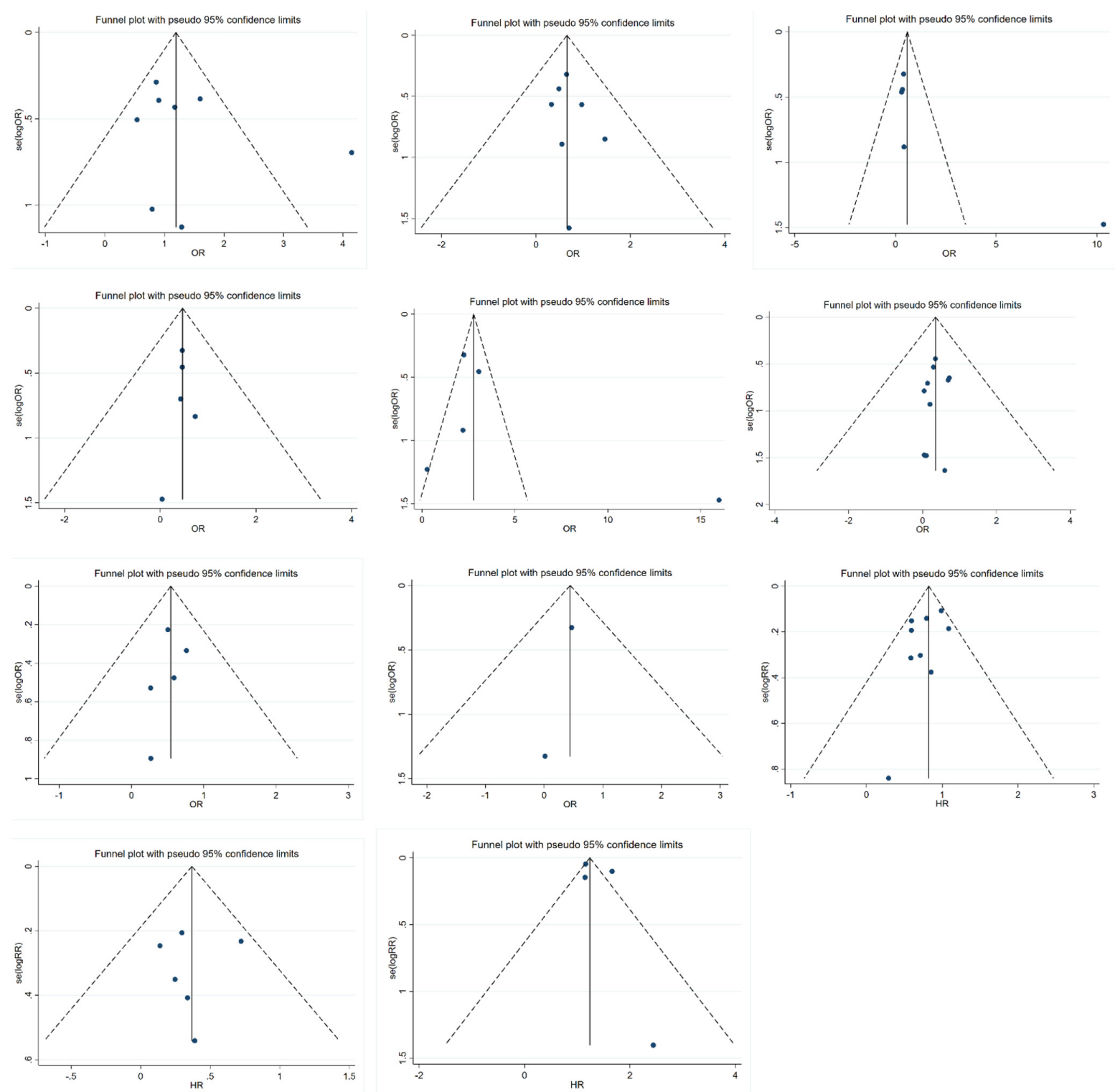

FIGURE 6 | Funnel plots of meta analysis.

high tumor stage and grade, lymph node metastasis, progression, recurrence, and papillary tumor, indicating it had the potential to become an ideal target for bladder cancer therapy.

More thorough mechanistic research should be carried out to investigate the function of HER2 in bladder cancer.

\section{DATA AVAILABILITY STATEMENT}

The original contributions presented in the study are included in the article/supplementary material. Further inquiries can be directed to the corresponding authors.

\section{AUTHOR CONTRIBUTIONS}

$\mathrm{KG}, \mathrm{YG}$, and $\mathrm{KL}$ conceived the idea of the study, did the literature search and selected the studies. KG and YG extracted the relevant information. BX and WQ have carefully revised the manuscript and refined the English writing. All authors contributed to the article and approved the submitted version.

\section{FUNDING}

The work was supported by the National Natural Science Foundation of China (No. 81772734, 81802935, 81872089). 


\section{REFERENCES}

1. Ferlay J, Soerjomataram I, Dikshit R, Eser S, Mathers C, Rebelo M, et al. Cancer Incidence and Mortality Worldwide: Sources, Methods and Major Patterns in GLOBOCAN 2012. Int J Cancer (2015) 136:E359-86. doi: $10.1002 /$ ijc. 29210

2. Siegel RL, Miller KD, Jemal A. Cancer Statistics, 2019. CA Cancer J Clin (2019) 69:7-34. doi: 10.3322/caac.21551

3. Siegel RL, Miller KD, Fuchs HE, Jemal A. Cancer Statistics, 2021. CA Cancer J Clin (2021) 71(1):7-33. doi: 10.3322/caac.21654

4. Cho KS, Seo HK, Joung JY, Park WS, Ro JY, Han KS, et al. Lymphovascular Invasion in Transurethral Resection Specimens as Predictor of Progression and Metastasisin Patients With Newly Diagnosed T1 Bladder Urothelial Cancer. J Urol (2009) 182(6):2625-30. doi: 10.1016/j.juro.2009.08.083

5. Sunil KA, Pedro E. Electrochemical ELISA-Based Platform for Bladder Cancer Protein Biomarker Detection in Urine. Biosens Bioelectron (2018) :620-7. doi: 10.1016/j.bios.2018.07.003

6. Olayioye MA, Neve RM, Lane HA, Hynes NE. The ErbB Signaling Network: Receptor Heterodimerization in Development and Cancer. EMBO J (2000) 19:3159-67. doi: 10.1093/emboj/19.13.3159

7. Yarden Y. Biology of HER2 and Its Importance in Breast Cancer. Oncology (2001) 61:1-13. doi: 10.1159/000055396

8. Wolff AC, Hammond MEH, Allison KH, Harvey BE, Mangu PB, Bartlett JMS, et al. Human Epidermal Growth Factor Receptor 2 Testing in Breast Cancer: American Society of Clinical Oncology/College of American Pathologists Clinical Practice Guideline Focused Update. J Clin Oncol (2018) 3620 (20):437-41. doi: 10.1200/JOP.18.00206

9. Janjigian YY, Maron SB, Chatila WK, Millang B, Chavan SS, Alterman C, et al. First-Line Pembrolizumab and Trastuzumab in HER2-Positive Oesophageal, Gastric, or Gastro-Oesophageal Junction Cancer: An OpenLabel, Single-Arm, Phase 2 Trial. Lancet Oncol (2020) 216(6):821-31. doi: 10.1016/S1470-2045(20)30169-8

10. Shitara K, Bang YJ, Iwasa S, Sugimoto N, Ryu MH, Sakai D, et al. Trastuzumab Deruxtecan in Previously Treated HER2-Positive Gastric Cancer. N Engl J Med (2020) 38225(25):2419-30. doi: 10.1056/NEJMoa2004413

11. Amin MB, McKenney JK, Paner GP, Hansel DE, Grignon DJ, Montironi R, et al. ICUD-EAU International Consultation on Bladder Cancer 2012: Pathology. Eur Urol (2013) 631:16-35. doi: 10.1016/j.eururo.2012.09.063

12. Zhao J, Xu W, Zhang Z, Song R, Zeng S, Sun Y, et al. Prognostic Role of HER2 Expression in Bladder Cancer: A Systematic Review and Meta-Analysis. Int Urol Nephrol (2015) 47:87-94. doi: 10.1007/s11255-014-0866-Z

13. Eissa S, Ali HS, Al Tonsi AH, Zaglol A, El Ahmady O. HER2/neu Expression in Bladder Cancer: Relationship to Cell Cycle Kinetics. Clin Biochem (2005) 38 (2):142-8. doi: 10.1016/j.clinbiochem.2004.09.004

14. Ding W, Tong S, Gou Y, Sun C, Wang H, Chen Z, et al. Human Epidermal Growth Factor Receptor 2: A Significant Indicator for Predicting Progression in Non-Muscle-Invasive Bladder Cancer Especially in High-Risk Groups. World J Urol (2015) 3312(12):1951-7. doi: 10.1007/s00345-015-1557-9

15. Kolla SB, Seth A, Singh MK, Gupta NP, Hemal AK, Dogra PN, et al. Prognostic Significance of HER2/neu Overexpression in Patients With Muscle Invasive Urinary Bladder Cancer Treated With Radical Cystectomy. Int Urol Nephrol (2008) 402(2):321-7. doi: 10.1007/s11255-007-9283-x

16. Krüger S, Weitsch G, Büttner H, Matthiensen A, Böhmer T, Marquardt T, et al. HER2 Overexpression in Muscle-Invasive Urothelial Carcinoma of the Bladder: Prognostic Implications. Int J Cancer (2002) 1025(5):514-8. doi: 10.1002/ijc.10731

17. Lim SD, Cho YM, Choi GS, Park HK, Paick SH, Kim WY, et al. Clinical Significance of Substaging and HER2 Expression in Papillary Nonmuscle Invasive Urothelial Cancers of the Urinary Bladder. J Korean Med Sci (2015) 308(8):1068-77. doi: 10.3346/jkms.2015.30.8.1068

18. Hegazy R, Kamel M, Salem EA, Salem NA, Fawzy A, Sakr A, et al. The Prognostic Significance of P53, P63 and HER2 Expression in Non-MuscleInvasive Bladder Cancer in Relation to Treatment With Bacille CalmetteGuerin. Arab J Urol (2015) 133(3):225-30. doi: 10.1016/j.aju.2015.05.001

19. Paul Chih HC, Hui JY, Yen HC, Chin CP. HER2 Amplification Distinguishes a Subset of Non-Muscle-Invasive Bladder Cancers With a High Risk of Progression. J Clin Pathol (2013) 662(2):113-9. doi: 10.1136/jclinpath-2012200944
20. El Ochi MR, Oukabli M, Bouaiti E, Chahdi H, Boudhas A, Allaoui M, et al. Expression of Human Epidermal Growth Factor Receptor 2 in Bladder Urothelial Carcinoma. BMC Clin Pathol (2017) 17:3. doi: 10.1186/s12907017-0046-z

21. Inoue M, Koga F, Yoshida S, Tamura T, Fujii Y, Ito E, et al. Significance of ERBB2 Overexpression in Therapeutic Resistance and Cancer-Specific Survival in Muscle-Invasive Bladder Cancer Patients Treated With Chemoradiation-Based Selective Bladder-Sparing Approach. Int J Radiat Oncol Biol Phys (2014) 902(2):303-11. doi: 10.1016/j.ijrobp.2014.05.043

22. Behnsawy HM, Miyake H, Abdalla MA, Sayed MA, Ahmed A-F, Fujisawa M, et al. Expression of Cell Cycle-Associated Proteins in Non-Muscle-Invasive Bladder Cancer: Correlation With Intravesical Recurrence Following Transurethral Resection. Urol Oncol (2011) 295(5):495-501. doi: 10.1016/ j.urolonc.2009.08.002

23. Olsson H, Fyhr IM, Hultman P, Jahnson S. HER2 Status in Primary Stage T1 Urothelial Cell Carcinoma of the Urinary Bladder. Scand J Urol Nephrol (2012) 462(2):102-7. doi: 10.3109/00365599.2011.637955

24. Moustakas G, Kampantais S, Nikolaidou A, Vakalopoulos I, Tzioufa V, Dimitriadis G, et al. HER-2 Overexpression Is a Negative Predictive Factor for Recurrence in Patients With Non-Muscle-Invasive Bladder Cancer on Intravesical Therapy. J Int Med Res (2020) 48(1):300060519895847. doi: 10.1177/ 0300060519895847

25. Soria F, Moschini M, Haitel A, Wirth GJ, Gust KM, Briganti A, et al. The Effect of HER2 Status on Oncological Outcomes of Patients With Invasive Bladder Cancer. Urol Oncol (2016) 34(12):533.e1-10. doi: 10.1016/j.urolonc.2016.07.006

26. Bolenz C, Shariat SF, Karakiewicz PI, Ashfaq R, Ho R, Sagalowsky AI, et al. Human Epidermal Growth Factor Receptor 2 Expression Status Provides Independent Prognostic Information in Patients With Urothelial Carcinoma of the Urinary Bladder. BJU Int (2010) 1068(8):1216-22. doi: 10.1111/j.1464410X.2009.09190.x

27. Abdelrahman AE, Rashed HE, Elkady E, Elsebai EA, El-Azony A, Matar I. HER2/neu, and E2F1 as Prognostic Markers of Progression in Non-Muscle Invasive Bladder Cancer. Ann Diagn Pathol (2019) 39:42-52. doi: 10.1016/ j.anndiagpath.2019.01.002

28. Tierney JF, Stewart LA, Ghersi D, Burdett S, Sydes MR. Practical Methods for Incorporating Summary Time-to-Event Data Into Meta-Analysis. Trials (2007) 8:16. doi: 10.1186/1745-6215-8-16

29. Higgins JPT, Green S. Cochrane Handbook for Systematic Reviews of Interventions Version 5.1. 0 [Updated March 2011]. In: The Cochrane Collaboration (2011) Available at: www.cochrane-handbook.org. (Accessed January 2017).

30. Sanguedolce F, Russo D, Mancini V, Selvaggio O, Calò B, Carrieri G, et al. Human Epidermal Growth Factor Receptor 2 in Non-Muscle Invasive Bladder Cancer: Issues in Assessment Methods and Its Role as Prognostic/ Predictive Marker and Putative Therapeutic Target: A Comprehensive Review. Urol Int (2019) 102(3):249-61. doi: 10.1159/000494359

31. Aizawa M, Nagatsuma AK, Kitada K, Kuwata T, Fujii S, Kinoshita T, et al. Evaluation of HER2-Based Biology in 1,006 Cases of Gastric Cancer in a Japanese Population. Gastric Cancer (2014) 17(1):34-42. doi: 10.1007/s10120-013-0239-9

32. Fan XS, Chen JY, Li CF, Zhang YF, Meng FQ, Wu HY, et al. Differences in HER2 Over-Expression Between Proximal and Distal Gastric Cancers in the Chinese Population. World J Gastroenterol (2013) 19(21):3316-23. doi: 10.3748/ wjg.v19.i21.3316

33. Sylvester RJ, van der Meijden A, Witjes JA, Jakse G, Nonomura N, Cheng C, et al. High-Grade Ta Urothelial Carcinoma and Carcinoma in Situ of the Bladder. Urology (2005) 66:90-107. doi: 10.1016/j.urology.2005.06.135

34. Witjes JA. Bladder Carcinoma In Situ in 2003: State of the Art. Eur Urol (2004) 45:142-6. doi: 10.1016/j.eururo.2003.09.013

35. Xylinas E, Rink M, Margulis V, Karakiewicz P, Novara G, Shariat SF. Multifocal Carcinoma In Situ of the Upper Tract Is Associated With High Risk of Bladder Cancer Recurrence. Eur Urol (2012) 615(5):1069-70. doi: 10.1016/j.eururo.2012.02.042

36. Fleischmann A, Rotzer D, Seiler R, Studer UE, Thalmann GN. HER2 Amplification Is Significantly More Frequent in Lymph Node Metastases From Urothelial Bladder Cancer Than in the Primary Tumours. Eur Urol (2011) 602(2):350-7. doi: 10.1016/j.eururo.2011.05.035

37. Lu Y, Jingyan G, Baorong S, Peng J, Xu Y, Cai S. Expression of EGFR, Her2 Predict Lymph Node Metastasis (LNM)-Associated Metastasis in Colorectal Cancer. Cancer Biomark (2012) 11(5):219-26. doi: 10.3233/CBM-2012-00282 
38. Kim D, Kim JM, Kim JS, Kim S, Kim KH. Differential Expression and Clinicopathological Significance of HER2, Indoleamine 2,3-Dioxygenase and PD-L1 in Urothelial Carcinoma of the Bladder. J Clin Med (2020) 95 (5):1265. doi: 10.3390/jcm9051265

39. Nedjadi T, Al-Maghrabi J, Assidi M, Dallol A, Al-Kattabi H, Chaudhary A, et al. Prognostic Value of HER2 Status in Bladder Transitional Cell Carcinoma Revealed by Both IHC and BDISH Techniques. BMC Cancer (2016) 16:653. doi: 10.1186/s12885-016-2703-5

40. Li P, Chen J, Miyamoto H. Androgen Receptor Signaling in Bladder Cancer. Cancers (Basel) (2017) 92(2):20. doi: 10.3390/cancers9020020

41. Zheng Y, Izumi K, Yao JL, Miyamoto H. Dihydrotestosterone Upregulates the Expression of Epidermal Growth Factor Receptor and ERBB2 in Androgen Receptor-Positive Bladder Cancer Cells. Endocr. Endocr Relat Cancer (2011) 184(4):451-64. doi: 10.1530/ERC-11-0010

42. Tripathi A, Gupta S. Androgen Receptor in Bladder Cancer: A Promising Therapeutic Target. Asian J Urol (2020) 7(3):284-90. doi: 10.1016/j.ajur.2020.05.011

43. Memon AA, Sorensen BS, Meldgaard P, Fokdal L, Thykjaer T, Nexo E, et al. The Relation Between Survival and Expression of HER1 and HER2 Depends on the Expression of HER3 and HER4: A Study in Bladder Cancer Patients. $\mathrm{Br}$ J Cancer (2006) 94(11):1703-9. doi: 10.1038/sj.bjc.6603154

44. Latif Z, Watters AD, Dunn I, Grigor KM, Underwood MA, Bartlett J. HER2/ neu Overexpression in the Development of Muscle-Invasive Transitional Cell Carcinoma of the Bladder. Br J Cancer (2003) 897(7):1305-9. doi: 10.1038/ sj.bjc. 6601245

45. Nagasawa J, Mizokami A, Koshida K, Yoshida S, Naito K, Namiki M. Novel HER2 Selective Tyrosine Kinase Inhibitor, TAK-165, Inhibits Bladder, Kidney and Androgen-Independent Prostate Cancer In Vitro and In Vivo. Int J Urol (2006) 135(5):587-92. doi: 10.1111/j.1442-2042.2006.01342.x

46. Tsai YS, Shiau AL, Chen YF, Tsai HT, Tzai TS, Wu CL. Enhancement of Antitumor Activity of Gammaretrovirus Carrying IL-12 Gene Through Genetic Modification of Envelope Targeting HER2 Receptor: A Promising Strategy for Bladder Cancer Therapy. Cancer Gene Ther (2010) 171(1):37-48. doi: $10.1038 / \mathrm{cgt} .2009 .41$

47. Tsai YC, Ho PY, Tzen KY, Tuan TF, Liu WL, Cheng AL, et al. Synergistic Blockade of EGFR and HER2 by New-Generation EGFR Tyrosine Kinase Inhibitor Enhances Radiation Effect in Bladder Cancer Cells. Mol Cancer Ther (2015) 143(3):810-20. doi: 10.1158/1535-7163.MCT-13-0951

48. Hayashi T, Seiler R, Oo HZ, Jäger W, Moskalev I, Awrey S, et al. Targeting HER2 With T-DM1, an Antibody Cytotoxic Drug Conjugate, Is Effective in
HER2 Over Expressing Bladder Cancer. J Urol (2015) 1944(4):1120-31. doi: 10.1016/j.juro.2015.05.087

49. Jack S, Madhivanan K, Ramadesikan S, Subramanian S, Edwards DF, Elzey BD, et al. A Novel, Safe, Fast and Efficient Treatment for HER2-Positive and Negative Bladder Cancer Utilizing an EGF-Anthrax Toxin Chimera. Int J Cancer (2020) 1462(2):449-60. doi: 10.1002/ijc.32719

50. Pietilä M, Sahgal P, Peuhu E, Jäntti NZ, Paatero I, Närvä E, et al. SORLA Regulates Endosomal Trafficking and Oncogenic Fitness of HER2. Nat Commun (2019) 10(1):2340. doi: 10.1038/s41467-019-10275-0

51. Tokumaru Y, Tajirika T, Sugito N, Kuranaga Y, Shinohara H, Tsujino T, et al. Synthetic miR-143 Inhibits Growth of HER2-Positive Gastric Cancer Cells by Suppressing KRAS Networks Including DDX6 RNA Helicase. Int J Mol Sci (2019) 207(7):1697. doi: 10.3390/ijms20071697

52. Cimpean AM, Tarlui V, Cumpănaş AA, Bolintineanu S, Cumpănaş A, Raica M. Critical Overview of HER2 Assessement in Bladder Cancer: What Is Missing for a Better Therapeutic Approach? Anticancer Res (2017) 37 (9):4935-42. doi: 10.21873/anticanres.11903

53. Franceschini T, Capizzi E, Massari F, Schiavina R, Fiorentino M, Giunchi F. Immunohistochemical Over-Expression of HER2 Does Not Always Match With Gene Amplification in Invasive Bladder Cancer. Pathol Res Pract (2020) 2168(8):153012. doi: 10.1016/j.prp.2020.153012

Conflict of Interest: The authors declare that the research was conducted in the absence of any commercial or financial relationships that could be construed as a potential conflict of interest.

Publisher's Note: All claims expressed in this article are solely those of the authors and do not necessarily represent those of their affiliated organizations, or those of the publisher, the editors and the reviewers. Any product that may be evaluated in this article, or claim that may be made by its manufacturer, is not guaranteed or endorsed by the publisher.

Copyright (c) 2021 Gan, Gao, Liu, Xu and Qin. This is an open-access article distributed under the terms of the Creative Commons Attribution License (CC BY). The use, distribution or reproduction in other forums is permitted, provided the original author(s) and the copyright owner(s) are credited and that the original publication in this journal is cited, in accordance with accepted academic practice. No use, distribution or reproduction is permitted which does not comply with these terms. 